\title{
COMO GOVERNAR O ÚNICO TEATRO DE ÓPERA EM PORTUGAL? \\ A incerteza permanente do estatuto do Teatro Nacional de São Carlos
}

\author{
Teresa Duarte Martinho \\ Instituto de Ciências Sociais da Universidade de Lisboa, Portugal \\ José Nuno Matos \\ Instituto de Ciências Sociais da Universidade de Lisboa, Portugal
}

\begin{abstract}
Resumo: Fundado em 1793, o Teatro Nacional de São Carlos (TNSC) é uma referência no campo da difusão e da produção de ópera em Portugal. Considerando o período entre 1974 e 2013, o presente artigo tem como principal objetivo compreender a evolução dos vários estatutos do TNSC e das lógicas que os enformam. A partir da análise de documentação jurídica, bem como de relatórios de gestão e de monografias dedicadas à história do referido teatro, é possível identificar ao longo deste período a oscilação entre dois paradigmas: o da gestão pública, que coloca a instituição sob a alçada direta do Estado, identificando neste modelo a melhor forma de assegurar o interesse público; o da gestão privada, defendendo que a satisfação do interesse público requer a indispensável participação de receitas empresariais em domínios sob responsabilidade estatal, em nome de maior eficácia orçamental. A relação entre estas duas lógicas, como será possível verificar, decorre no quadro de processos de maior amplitude, sendo indissociável de mutações nas políticas culturais e noutras esferas da sociedade.
\end{abstract}

Palavras-chave: Teatros de ópera; Políticas culturais; Gestão; Mecenato; Nova Gestão Pública.

\section{Introdução}

Este artigo $^{1}$ tem como principal objetivo traçar e compreender a evolução do estatuto e das lógicas de gestão do Teatro Nacional de São Carlos (TNSC) nas últimas quatro décadas, em que oscilou entre empresa pública, fundação, instituto público e parte integrante de agrupamento empresarial. Inaugurado em 30 de junho de 1793, a sua relevância no panorama cultural e artístico português advém principalmente de ser o único teatro nacional vocacionado para a produção e apresentação de ópera e de música coral e sinfónica. Os atuais agrupamentos artísticos residentes são o Coro do TNSC, que interpreta repertório operático e coral-sinfónico, mantendo-se como a única

${ }^{1} \mathrm{O}$ artigo prolonga um tópico abordado pelos autores no âmbito de uma pesquisa mais abrangente sobre $\mathrm{o}$ sector da cultura em Portugal (Garcia et al, 2014). 
estrutura coral profissional em Portugal tutelada pelo Estado; e a Orquestra Sinfónica Portuguesa.

Uma vez que as políticas culturais, na Europa e também em Portugal, contemplam entre os seus objetivos a preservação do património, o apoio à produção e criação artística e, mais recentemente, o incentivo ao envolvimento da sociedade civil no apoio financeiro à cultura, afigura-se valiosa uma análise dos modos como o Estado português tem desempenhado tais responsabilidades naquele que é o único teatro nacional de ópera. É característica destas estruturas artísticas, como vários estudos têm evidenciado, uma manutenção particularmente exigente, quer pelos elevados custos de funcionamento e de produção, quer pela coexistência de perfis profissionais diferenciados - artísticos (intérpretes, encenadores); técnico-artísticos (profissionais que prestam apoio técnico aos intérpretes e encenadores); mediação (gestão, administração, divulgação) - obrigando a um constante processo de negociação no teatro de ópera (Martorella, 1982; Atkinson, 2006).

A análise abrange o período desde a introdução do regime democrático, em 1974, até ao presente e incide especialmente na produção legislativa sobre o tópico enunciado. A abordagem aqui proposta procura averiguar de que forma as várias opções de gestão tomadas para o TNSC se relacionam com as políticas dos sucessivos governos constitucionais. A análise empreendida parte de dois pressupostos. Em primeiro lugar, argumenta-se que os princípios orientadores da gestão, mais do que limitarem-se a um conjunto de pressupostos meramente técnicos, correspondem a propostas de organização e cultivam determinados tipos de relações sociais de produção. Em segundo, sublinha-se que a multiplicidade de modelos de política cultural, a tensão que rodeia o exercício da função cultural do Estado (Ramos, 2011) e as previsíveis descontinuidades estratégicas das políticas apenas são plenamente compreendidas se não forem destituídas das suas referências ideológicas (Silva, 2003).

O corpus de análise privilegiado neste estudo - a produção legislativa sobre o estatuto do TNSC e o discurso jurídico tecido à sua volta - exemplifica o cariz político inerente a um dispositivo de poder como são os diplomas legais. Não obstante a cristalização das suas categorias e a natureza autoritária da sua palavra (Bakhtin, 2007: 32), cuja interpretação é circunscrita a um grupo de especialistas outorgados e qualificados, é possível submeter o discurso jurídico a uma análise que o confronta com o seu percurso histórico e ainda com a interação com outro tipo de discursos e práticas. Trata-se, afinal, de reconhecer que "as soluções jurídicas são sempre contingentes em relação a um dado envolvimento" (Hespanha, 1997: 15). A contingência histórica e social do discurso jurídico é reconhecível nas alterações de estatutos que o TNSC denota no seu percurso 
nos últimos quarenta anos. Através da análise das sucessivas alterações é possível detetar a mudança de lógicas de gestão e ainda o surgimento de novas categorias e variáveis de análise.

Embora a análise privilegie os diplomas legislativos, incide ainda em programas governamentais, relatórios de atividades e contas do TNSC, obras monográficas e textos de imprensa. Com a ampliação de fontes pretendeu-se expandir a compreensão da evolução das modalidades de gestão do TNSC e captar as vozes dos diversos agentes implicados nestes processos, desde os decisores políticos a diversas categorias de profissionais do teatro - estes acumulando, por vezes, o papel de fazedores da sua história. O artigo estrutura-se em duas secções principais, servindo de separador a criação, em 1995, do Ministério da Cultura, incumbido de definir e executar uma política para o setor cultural e que se manteve nas orgânicas governamentais até à tomada de posse do XIX executivo, em 2011².

\section{De empresa pública a fundação (1974 -1993)}

O TNSC foi inaugurado, em Lisboa, em 30 de junho de 1793, ainda em fase de obras não acabadas; tornou-se, desde então, o centro exclusivo do repertório lírico italiano em Portugal (Nery e Castro, 1999).

Importa, de forma sintética, abordar a génese do teatro e os motivos da sua edificação. De facto, o cruzamento de interesses de diferentes atores sociais, em torno do projeto, revela interações entre o que atualmente se designa setores 'público' e 'privado', isto na sociedade portuguesa da segunda parte do século XVIII, com as especificidades sociopolíticas da época. Torna-se percetível que o plano deste teatro de ópera estruturou-se em torno das ideias de celebração, continuidade e espírito empresarial, articuladas pela intervenção dos vários mentores e patrocinadores.

Celebração, na medida em que a construção do TNSC encarnava o desígnio de festejar a aguardada continuidade da dinastia reinante, concretizada no nascimento da infanta D. Maria Teresa de Bragança, que teve lugar em abril de 1793 (Seabra, 1993; Cruz, 2008; Cymbron, 2009). O projeto arquitetónico, de José da Costa e Silva, inspirava-se nos grandes teatros de ópera italianos da época e a construção iniciou-se em dezembro de 1792. O novo teatro era incorporado na Casa Pia de Lisboa, de modo a contribuir para a sua subsistência; em 1854, deixou de estar integrado naquela instituição e ficou definitivamente na posse do Estado. Continuidade, pois faltava a Lisboa um espaço que substituísse a Ópera do Tejo, um teatro de corte estreado em 31 de março de 1775 e

${ }^{2}$ Assinale-se a instituição, em 1983, pelo IX governo, de um ministério exclusivo para a cultura, que viria a ser extinto em 1985. 
destinado a afirmar o poder régio em Portugal (Brito, 1989), que teria fim imposto pelo terramoto de 1 de novembro do mesmo ano (Seabra, 1993; Nery e Castro, 1999) ${ }^{3}$. Espírito empresarial, pelo facto de um grupo de financeiros, tendo como mentor e figura agregadora o Intendente-geral da polícia, Diogo Inácio de Pina Manique (17331805), ter aderido à ideia de um novo e grandioso teatro de ópera em Lisboa e avançado com o financiamento. Este núcleo de homens de negócios estaria mobilizado pelo investimento na sociabilidade que este edifício público podia proporcionar à burguesia lisboeta (Nery e Castro, 1999; Carvalho, 1993).

Apesar da gestão do TNSC ter sido entregue a empresários, os sucessivos governos atribuíram-lhe significativo apoio financeiro, através de subsídios ou de verbas de lotarias (Cymbron, 2009); isto, para além de, no século XIX, o Estado ter tido intervenção direta em situações de falência de empresas gestoras do funcionamento do teatro (conforme preâmbulo do Decreto-Lei no 35775, de 31 de Julho de 1946). Na figura de proprietário, o Estado também apresentou falhas, como no caso, designadamente, do agravamento da situação económica do teatro por altura do seu primeiro centenário, com a suspensão do subsídio estatal (Nery e Cruz, 1999).

A década de 40 do século XX consolidou a marca distintiva inicial do S. Carlos, fomentando-se a imagem de um teatro frequentado maioritariamente pela elite social e acedido mediante normas restritivas: do uso obrigatório de traje de cerimónia nas récitas de estreia à disparidade do custo dos bilhetes por tipo de lugar, garantindo a exibição da diferenciação social dos espetadores (Ribeiro, 2012). A reabertura do TNSC, em dezembro de 1940, depois de obras de requalificação de grande vulto, integrou-se nos festejos dos centenários da fundação e da restauração da independência do país, num cerimonial que perpetuava o seu prestígio hierárquico no campo musical em Portugal (Carvalho, 1993). Na celebração dos 150 anos do teatro, em 1943, foi adotada a designação de Teatro Nacional de São Carlos.

Em 1946, o Decreto-Lei ${ }^{0}$ 35775, de 31 de julho, colocou-o sob administração direta do Estado, ficando subordinado ao Ministério da Educação Nacional e na dependência da Direção-Geral do Ensino Superior e das Belas-Artes. Com tal mudança, procurava-se estabelecer as condições necessárias para o "cumprimento da sua missão cultural, fazendo dele o fulcro da atividade musical portuguesa" (Decreto-Lei ${ }^{\circ} 35775$, de 31 de julho). Data simbólica, uma vez que aquela alteração fez com que o Estado acumulasse, desde então, e no âmbito da sua tarefa genérica de regulador das atividades culturais e

\footnotetext{
3 Para uma visão do panorama da atividade operática nesta época, em Portugal, bem como dos espaços que acolhiam espetáculos músico-teatrais, ver as seguintes obras: Brito, 1989; Moreau, 1999; Nery e Castro, 1999; Cruz, 2008.
} 
artísticas, os papéis de proprietário, gestor, administrador, empresário e programador (Cummings e Katz, 1989).

No longo diário das temporadas do TNSC que Mário Moreau (n.1926)4 exaustivamente elaborou (Moreau, 1999), o relato da época 1973-74 encerra mencionando o profundo impacto da revolução de 25 de Abril de 1974 na vida do país, salientando dois resultados "imediatos" para o teatro. Em consonância com a tendência para o quebrar de convenções de que a democracia era portadora, cessava a obrigatoriedade de usar traje de cerimónia nas récitas de estreia, quase sempre noturnas. A outra imediata consequência da mudança de regime operou-se na direção do teatro. João Paes (19281963) substituiu João de Freitas Branco (1922-1989), que dirigia o TNSC desde 1970 e passou a integrar o III governo provisório, como secretário de estado da Cultura e Educação Permanente. De notar que o programa daquele governo, chefiado por Vasco Gonçalves, apontava a necessidade de reestruturar os teatros nacionais, com o desígnio de atingir "pleno rendimento cultural ao serviço de parcelas muito mais vastas de população" (Programa do III governo provisório). O TNSC entrava num período marcado por indecisões políticas quanto ao seu estatuto e funcionamento (Cymbron, 2009), num cenário de fundo em que "a revolução não corria na cultura tão depressa como se queria” (Dionísio 1993: 214). Em Ir a S. Carlos, Augusto M. Seabra defende que, em continuidade com a I República - para a qual o S. Carlos foi "uma questão atravessada”, pela identificação do hábito de ir à opera com a monarquia - a democracia pós-25 de Abril "nunca soube bem o que fazer de S. Carlos" (Seabra, 1993: 99).

Se os rumos para a cultura e para as estruturas na sua dependência, como os teatros nacionais, permaneciam numa situação de predominante indeterminação, para o TNSC a segunda metade da década de 70 foi uma época movimentada do ponto de vista organizacional, influenciando a reconfiguração do campo da ópera em Lisboa. Tempo de reajustamentos, alavancados principalmente pelo projeto, do novo diretor do TNSC, de dar início à "instalação dos Corpos artísticos e técnico-profissionais Residentes: orquestra, cantores, cenografia, etc." (Cruz, 1992: 80). O TNSC foi dotado com uma orquestra (Orquestra Filarmónica de Lisboa) e acolheu os cantores portugueses que atuavam desde 1963 na Companhia Portuguesa de Ópera (CPO), extinta em 1975. Com sede no Teatro da Trindade e enquadrada nas atividades da Fundação Nacional para a Alegria no Trabalho (FNAT), esta Companhia operática, dirigida por José Serra Formigal (1925-2011), constituíra um centro de oportunidades para a carreira de um conjunto de agentes artísticos portugueses e iniciou um significativo processo de

\footnotetext{
${ }_{4}^{4}$ Investigador e diretor-geral do TNSC, de 1982 a 1984.
} 
difusão da ópera (Domingos, 2007). A nova direção da FNAT, que passou a designar-se Inatel, fundamentava a decisão da extinção da CPO com a justificação de que era missão do TNSC prosseguir o esforço que o Teatro da Trindade até aí desenvolvera na área da ópera (Ibidem, 205). Em junho de 1977, foi criada a Companhia Nacional de Bailado (CNB), que viria a participar na programação das temporadas seguintes do TNSC (Moreau, 1999). O TNSC expandia-se, tornando-se mais diversificado em perfis artísticos e técnico-artísticos. Mas, apesar da manifesta expansão, alguns consideravam que as potencialidades desta estrutura produtiva não eram adequadamente fomentadas (Carvalho, 1993).

As redefinições estatutárias do TNSC, consagradas em lei entre 1979 e 1980, reconheceram e vieram formalizar a afirmação do teatro como estrutura de produção e criação artística. Este tipo de reestruturação sinaliza também, por parte do Estado, uma crescente atenção à definição dos instrumentos de regulamentação do apoio e financiamento das artes e da cultura. Assim, em 1979, o V governo constitucional atribuiu ao TNSC, e a outras estruturas na dependência da Secretaria de Estado da Cultura (SEC), o estatuto legal de instituto público, dotado de autonomia administrativa e financeira (Decreto-Lei $n^{0} 533 / 79$, de 31 de dezembro). Visava-se "abrir caminhos que facilitem as atividades culturais, sobretudo aquelas que necessitam de um efetivo apoio estatal”, encarando a institucionalização do TNSC, do Teatro Nacional de D. Maria II e de outras entidades em organismos "autónomos e desburocratizados" como condição da sua transformação "em agentes efetivos de uma política cultural dinamizadora no âmbito de todo o espaço cultural português”. No preâmbulo do diploma mencionado, valorizam-se os princípios da autonomia e de desburocratização, considerando a autonomia financeira como facilitadora de "liberdade criativa” e "conquista de um público".

O processo de reconhecimento, que a produção legislativa denota, culmina em 1980 com a instituição de uma empresa pública denominada Teatro Nacional de S. Carlos, E. P. (Decreto-Lei $n^{0}$ 259/80, de 5 de agosto), num caso similar ao que outros teatros nacionais vivenciaram. Segundo a lei, as alterações no trajeto do TNSC nos últimos anos, tinham-lhe permitido "alinhar ao lado das salas de ópera mais importantes da Europa”, estando em falta uma "correspondente revisão de leis, estruturas e quadros, sem a qual o progresso já verificado estiolará necessariamente”. A transformação do TNSC em empresa pública aproximava-o, segundo o diploma, do regime de autonomia praticada em instituições congéneres europeias e proporcionaria uma maior "flexibilidade de gestão e impedindo o anquilosamento das carreiras artísticas". Salienta-se, de novo, a visão de uma relação estreita entre autonomia - administrativa, 
financeira e patrimonial - e flexibilidade de gestão e o cuidado na administração das carreiras profissionais. Contas, contratos e outras operações ficavam isentos do julgamento e da aprovação do Tribunal de Contas e da Direcção-Geral da Contabilidade Pública.

Logo no ano seguinte, em 1981, os termos do diploma que instituíra o Teatro Nacional de S. Carlos, E. P. eram alterados. Com efeito, o Decreto-Lei ${ }^{0}$ 123/81, de 25 de maio, procedeu a um reajuste nos papéis internos, declarando desadequado o facto de o presidente do conselho de gerência do teatro deter simultaneamente a responsabilidade direta e exclusiva pela orientação e direção artística. Tal acumulação gerara a "maioria das dificuldades com que teve de confrontar-se a gestão da empresa durante os últimos meses" (Moreau, 1999: 216), de acordo com o secretário-geral da Cultura.

A evolução do TNSC nos anos 80 evidencia um caminho no sentido da profissionalização dos seus elementos, incluindo a vinculação contractual no teatro, numa tendência quase exclusiva das carreiras artísticas prosseguidas em organizações de maior escala, como orquestras sinfónicas e teatros de ópera (Menger, 1999). De registar, nesta década, a ocorrência de conflitos laborais que opuseram os trabalhadores e o governo, como sucedeu na temporada 1982-83, e alguns episódios conflituais entre diferentes departamentos do TNSC, particularmente agudizados no período de 1988 a 1992 (Moreau, 1999; Cruz, 1992). Excetuando o eventual efeito de resquícios do clima pós-revolucionário, tais conflitos não são alheios ao funcionamento dos teatros de ópera, quer pela complexidade organizacional característica destas estruturas, onde é frequente a tensão entre as lógicas de produção na gestão/administração e os valores artísticos que orientam a criação, quer ainda pelo forte desfasamento entre as despesas e os rendimentos associado à produção deste género de espetáculo (Martorella, 1982; Atkinson, 2006).

A mencionada fase das temporadas de 1988-89 a 1991-1992 decorreu num "clima de hostilidades" (Moreau, 1999: 229) entre a administração e outros setores, como a orquestra, em consequência do que terá sido a "desastrosa gestão, administrativa e artística, iniciada em Agosto de 1988” (Cruz 1992: 4). A temporada de 1991-1992 registou o fim do regime de empresa pública, sendo criada uma fundação de direito privado e utilidade pública, a Fundação de São Carlos, a que foi entregue a responsabilidade da conservação do teatro, da produção de espetáculos de ópera, da manutenção da Orquestra Sinfónica Portuguesa, criada em 1993, e da Companhia Nacional de Bailado (Decreto-Lei ${ }^{0}$ 75/93, de 10 de março). Repare-se, nos seguintes depoimentos, no contraste das perspetivas expressas pelo responsável pela decisão, por um lado, e por um trabalhador da empresa extinta, o maestro Manuel Ivo Cruz (1935- 
2010), por outro lado. No primeiro depoimento, é reconhecível um argumento próliberal e no segundo denuncia-se a colocação dos trabalhadores na precariedade e o derrube de um projeto de estabilidade:

"[a subsecretária adjunta do secretário de estado da cultura do XII governo] tomou uma primeira medida polémica: a extinção da empresa pública do Teatro Nacional de São Carlos [que] era uma empresa pública falida. (...). Porque as carreiras artísticas funcionavam como no resto da função pública: utilizava-se a mesma progressão na carreira e, à medida que envelheciam, os artistas ganhavam mais e produziam menos. (...) Maria José [Nogueira Pinto] desejava dar uma vida própria a cada departamento e pretendeu libertar o orçamento [do TNSC] para este se dedicar sobretudo à ópera, que era a sua vocação primeira: 'Percebemos que, com as regras da função pública, era impossível executar aquele programa, portanto constituir uma fundação era uma forma de resolver a questão e [...] conseguir por o teatro a funcionar' (...) Defensora da libertação dos agentes culturais do poder do Estado, Maria José foi, portanto, a responsável pela passagem do Teatro Nacional empresa pública - a Fundação" (Câmara, 2013: 136-137)

“(...) o caos instalou-se na Empresa Pública do Teatro Nacional de S. Carlos, proporcionando ao Governo a sua extinção nos termos de um decreto recentemente aprovado pelo Tribunal Constitucional, acarretando a dissolução dos vínculos laborais que garantiam os postos de trabalho aos Artistas profissionais dos seus diversos quadros orgânicos - depois de 4 anos de públicos vexames, desconsiderações e injustificadas quebras no fluir das carreiras. Pena é que, na véspera da celebração do seu II Centenário e no limiar da plena vivência de Portugal na Comunidade Europeia, o S. Carlos não seja hoje mais do que o cemitério das radiosas esperanças de destino europeizante, abertas aos profissionais portugueses pelas Administrações anteriores (...)” (Cruz, 1992: 4).

O modelo da fundação, tal como o diploma que a instituiu permite constatar, tinha por finalidade concretizar a colaboração, considerada indispensável, da sociedade civil, "através da participação desinteressada de agentes económicos privados, que possam contribuir com os seus conhecimentos e experiência para este propósito generoso" (Decreto-Lei $\mathrm{n}^{0} 75 / 93$, de 10 de março). O conjunto de fundadores integrava o Estado e algumas empresas públicas e privadas - Radiodifusão Portuguesa, E. P.; Radiotelevisão Portuguesa, S. A. ; SOMEC, Sociedade Metropolitana de Construções, S. A.; TLP, Telefones de Lisboa e Porto, S. A. ; Banco Comercial Português, S. A - e o desígnio principal da Fundação de São Carlos consistia no auto-financiamento do teatro. Os diplomas que instituíram esta e outras fundações participadas pelo Estado 
reafirmavam conceções igualmente presentes na que foi apresentada, em 1986, como Lei do Mecenato (Decreto-Lei $\mathrm{n}^{0}$ 258/86, de 28 de agosto), segundo a qual o apoio financeiro à criação, à ação e à difusão cultural, não devia constituir competência exclusiva dos poderes públicos. Este diploma, apontando para a atribuição de incentivos fiscais como contrapartida do patrocínio empresarial a atividades de reconhecido mérito cultural, surgiu na continuidade de um discurso acentuado na sociedade portuguesa a partir de meados dos anos 80. Como pode ler-se no programa do X governo constitucional - que tomou posse em novembro de 1985 , iniciando um ciclo de dez anos de governos sociais-democratas -, na secção dedicada à cultura, verifica-se um explícito direcionamento na promoção da participação empresarial no apoio à cultura:

"O patrocínio particular e empresarial, facto social de crescente dimensão dos países europeus, contribuiu para o dinamismo da vida cultural e para a desejável diversificação das fontes de apoio. O Governo procurará corresponder a esta tendência quer através de medidas jurídicas e fiscais, quer facultando informações e contactos relativamente a projectos susceptíveis de virem a ser patrocinados" (programa do $\mathrm{X}$ governo constitucional).

No final dos anos 1980, a ação social empresarial passou, pois, a ser incentivada a partir do dispositivo legal que instituiu o mecenato cultural, o qual criava "condições capazes de permitir aos particulares apoiar decididamente a criação cultural portuguesa [definindo um quadro de deduções fiscais]", isto dada a "especial responsabilidade" de toda a comunidade no apoio financeiro à criação, à ação e à difusão cultural (Decreto-Lei $\mathrm{n}^{0}$ 258/86, de 28 de Agosto5). A Lei do Mecenato colocou o setor empresarial como importante financiador da cultura, através da atribuição de donativos ou de outro tipo de apoio financeiro a organizações culturais, numa intervenção simultaneamente complementar e extensiva da ação do Estado. Enquanto lugares de produção e acumulação económica, as empresas distanciavam-se das figuras individuais e da relação tutelar que caracterizara fases anteriores do mecenato, podendo até ver-se neste seu modo de participar na comunidade a face externa de uma 'cultura de empresa' (Santos e Conde, 1990). Num inquérito às empresas portuguesas, realizado em 1988, com a finalidade de conhecer os seus interesses no mecenato e, mais concretamente, na Lei de 1986, sobressai, entre outros resultados, que as empresas beneficiavam mais os bens culturais de elevado prestígio, fossem eles expressões de

\footnotetext{
5 De notar que, desde 1986, a legislação foi objeto de diversas alterações. O mecenato cultural foi regulado pelo Estatuto do Mecenato (Decreto-Lei $\mathrm{n}^{\circ}$ 74/99, de 16 de março) e é atualmente abrangido pelo Estatuto dos Benefícios Fiscais (Decreto-Lei no 108/2008, de 26 de junho).
} 
cultura contemporânea ou géneros culturais clássicos (ópera e música erudita ou património histórico) (Ibidem).

Com a passagem de empresa pública a fundação, o TNSC protagonizava o que foi considerado um ensaio do princípio da desestatização aplicado à gestão de espaços culturais (Henriques, 2002). No campo dos media, fora aberta, em 1990, a possibilidade de criação de canais televisivos privados, resultante da revisão constitucional de 1989 (Lei Constitucional $n^{0} 1 / 89$ de 8 de julho), que colocou fim à garantia das nacionalizações e conferiu ao sistema económico maior flexibilidade (Marques, 1990). E como acima se viu, já na década de 80 se disseminava na sociedade portuguesa o discurso incentivador da assunção de responsabilidades pela sociedade civil no apoio e financiamento dos serviços tradicionalmente assegurados exclusivamente pelo Estado. Não por acaso, o apelo e o incentivo a parcerias públicoprivadas emergem e reforçam-se tendo por fundo a vigência de governos sociaisdemocratas, sendo de assinalar que o XI governo, eleito em 1987, foi o primeiro executivo monopartidário (Partido Social Democrata, PSD) com apoio parlamentar maioritário desde 25 de Abril de 1974. Data também de meados dos anos 80 a formalização da adesão de Portugal à Comunidade Europeia, cujas instâncias relevantes na definição de políticas, como a Comissão Europeia, promoviam, desde os anos 80, ações sobre a importância de modalidades de financiamento privado da cultura - incluindo mecenato de empresa e outras modalidades de investimento privado na cultura, como as intervenções de fundações (terceiro setor) e de individuais.

Em suma, em consonância com o que se observara anteriormente noutros países europeus (Grã-Bretanha, Itália, Noruega, Suíça, Espanha, França, entre outros), onde o modelo Estado-Providência fora desgastado pela crise económica dos anos 70, também em Portugal um novo ciclo na vida política e económica, inaugurado em meados dos anos 80, tornou notória a preocupação em desestatizar os serviços públicos e promover e regulamentar a aproximação entre o setor empresarial e o sector cultural.

\section{De instituto público a agrupamento complementar de empresas (1995- 2013)}

O Decreto-Lei $\mathrm{n}^{\circ} 88 / 98$, de 3 de abril, que concretiza mais uma viragem no estatuto legal do TNSC, começa por apontar críticas aos anteriores diplomas. O estatuto de empresa pública, introduzido em 1980, revelara-se desadequado ao cariz do organismo em causa, "no qual a desproporção inevitável entre uma reduzida capacidade de gerar receitas próprias e elevados custos de operação implicava, à partida, uma exploração permanentemente deficitária" (Decreto-Lei $n^{0}$ 88/98, de 3 de abril). A sua falta de 
operacionalidade conduzira à transformação do teatro em fundação de direito privado e utilidade pública. Porém, como se pode ainda ler no preâmbulo do Decreto-Lei $\mathrm{n}^{\mathrm{o}}$ 88/98, de 3 de abril, esse estatuto viria a pautar-se pela "clara inadequação do modelo funcional (...) às finalidades que lhe eram atribuídas” (Ibidem). A fraca adesão do capital privado à condição de mecenas, aliada a um Estado que se considerava "isento de uma responsabilidade essencial pelo funcionamento do TNSC" (Ibidem), contribuiu para a acumulação de passivos financeiros e, consequentemente, para a diminuição da sua atividade. Os resultados do modelo 'fundação' ficariam, de facto, aquém do desejado, continuando o Estado a ser o principal contribuinte para o funcionamento desta estrutura, que denotava estruturalmente problemas de insuficiência orçamental (Santos et al., 1998; Henriques, 2002).

Após uma sumária análise crítica das fórmulas estatutárias aplicadas por governos anteriores, o diploma apontava as vantagens associadas ao novo estatuto do TNSC, que passava a instituto público. Três anos volvidos da criação do ministério da Cultura, no XIII governo, reforçado por um aumento de dotação orçamental para esta área ${ }^{6}$, o regresso à tutela pública do TNSC surge enquadrado numa "missão de serviço público cultural", cuja relevância justifica a (re)atribuição de autonomia administrativa e financeira. Contudo, o documento não deixa de aludir ao "esforço paralelo indispensável de angariação de financiamentos complementares no seio da sociedade civil” (Decreto-Lei no 88/98, de 3 de abril).

Embora refletisse, quando comparada com as estratégias delineadas por governos precedentes, a afirmação de uma política estrutural pública para a cultura, a nova condição institucional do organismo não destoava de um paradigma de gestão cada vez mais dominante. Ao nível das relações de trabalho, a título de exemplo, a lei instituiu um sistema misto, prevendo a aplicação do regime da função pública aos funcionários administrativos e o do contrato individual de trabalho aos profissionais dos departamentos técnicos e artísticos. Tal divisão pretendia a "conjugação dos objetivos de rigor indispensáveis na gestão dos dinheiros públicos com uma flexibilidade de funcionamento própria da produção de espetáculos de alto nível artístico, segundo padrões internacionais de excelência” (Ibidem). Esta 'excelência' assentava na aplicação de uma "filosofia de gestão" que, entre outros princípios, visava a "desburocratização dos processos de trabalho, nomeadamente através do recurso às novas tecnologias de informação" (Ibidem).

\footnotetext{
${ }^{6}$ A partir de 1995 verificaram-se aumentos das percentagens do Orçamento de Estado dedicadas à tutela da cultura na ordem dos $0,5 \%$ e $0,6 \%$. Esta tendência manteve-se até 2006, data a partir do qual se constante uma queda no financiamento público (Garcia et al., 2014: 47).
} 
Num contexto de crescimento económico, em que o país procurava visibilidade internacional através de grandes eventos culturais, como a Exposição Internacional de Lisboa de 1998, o novo estatuto do TNSC traduzia objetivos mais latos, que ultrapassam a própria esfera cultural. A eleição da internacionalização, da formação profissional ou da criação de novos públicos como objetivos de politica cultural enunciavam-se, agora, num quadro de crescente interdependência entre cultura e economia, apontando para a inscrição da cultura em lógicas que "direccionam a sua dinâmica para outros fins" (Morató, 2010: 46). Não obstante as reviravoltas institucionais que atravessaram o TNSC, a década de 90 será, em termos de intervenção estatal na cultura, marcada por três tendências essenciais: desmonopolização, privatização e liberalização. São delas expressão, designadamente, o reforço de parcerias público-privadas, evidenciado pela criação de fundações - como a Fundação das Descobertas, em 1991 (que passou, em 1999, a Fundação Centro Cultural de Belém) ou a Fundação de Serralves, em 1989 - e a introdução de critérios economicistas no financiamento e gestão pública da cultura (Henriques, 2002).

Esta lógica irá intensificar-se a partir de 2003, sob o XV governo, de coligação PSD/ Partido Popular (PP), com a aprovação do Orçamento de Estado a prever a perda de autonomia financeira dos institutos públicos, passando estes a deter autonomia meramente administrativa (Lei $\mathrm{n}^{0}$ 32-B/2002, de 30 de dezembro). O TNSC seria um dos 11 institutos públicos do Ministério da Cultura a ser visado por esta medida.

Mais tarde, aquando da vigência do XVII governo (Partido Socialista), o TNSC viria a ser objeto de nova reformulação estatutária. A aprovação do Programa de Reestruturação da Administração Central do Estado (PRACE), em 2005, implicaria mudanças em todos os seus organismos, com a exceção dos corpos policial e militar. Aquele programa, segundo a análise de Juan Mozzicafredo e Carla Gouveia, apresentava como principais metas: a reestruturação da administração direta e indireta, em função da natureza dos ministérios; a reorganização das suas funções, com eventual recurso à subcontratação de serviços; ou a concentração física dos serviços públicos, de forma a criar economias de escala e, assim, proporcionar a partilha de serviços a nível interministerial (Mozzicafredo e Gouveia, 2011).

A menção ao "esforço de racionalização estrutural" surge, de facto, logo nas primeiras linhas do Decreto-Lei $n^{0}$ 160/2007, de 27 de abril, o qual cria o Organismo de Produção Artística, Entidade Pública Empresarial (OPART, E.P.E.), composto pelo TNSC e pela CNB. A resolução do problema da perda de autonomia financeira dos institutos públicos, passará, assim, no caso do TNSC, pela sua transformação em empresa pública, por um lado, e pelo incentivo à partilha de recursos com a $\mathrm{CNB}$, dada 
a interseção entre a ópera e o bailado, por outro. Esta opção era justificada pelo facto de a atividade dos organismos ter como pressuposto a existência de "instrumentos de gestão empresarial, sem os quais não é possível promover a sustentabilidade dos projetos e o efeito reprodutivo do investimento, na sua dupla dimensão cultural e económico-financeira" (Decreto-Lei $n^{0}$ 160/2007, de 27 de abril). O artigo $3 .^{\circ}$ dos seus estatutos vem reforçar esta dupla dimensão, sujeitando a empresa aos poderes de superintendência e tutela dos ministérios das Finanças e da Cultura, com base num contrato-programa7 que define os seus direitos e obrigações.

No primeiro relatório de gestão e contas (2007), o então presidente do Conselho de Administração (CA) do OPART, Pedro Santos Moreira (n.1970) ${ }^{8}$ realçava o cariz "particularmente relevante e inédito [da OPART] no setor da cultura em Portugal", uma vez que se estava, na sua visão, perante um processo que implicava a transmutação de princípios de gestão empresarial para uma entidade que, apesar dos vários episódios da sua evolução, era, à altura, um instituto público. Para a realização desta operação, anunciavam-se seis linhas de orientação, no horizonte 2008-2009: "garantia dos padrões de excelência das prestações artísticas"; "aumento do volume de atividade artística"; "captação de novos públicos e abertura à sociedade civil”; "dinamização de atividades conjuntas"; "aumento das receitas próprias" e a já mencionada "organização e a qualificação dos seus membros” (OPART, 2007: 29).

O reconhecimento da responsabilidade de Diretores Artísticos na "manutenção dos padrões de excelência” não excluía a preponderância de objetivos a atingir, prédeterminados no contrato-programa. Apesar de se admitir a sua "difícil mensuração (p. e. notoriedade das marcas, angariação de novos públicos, formação de novos artistas) ” (Ibidem: 17), estes objetivos denotam a enfase no quantitativo, sendo a atividade desenvolvida avaliada à luz do número de espetáculos apresentados e do volume de espetadores obtidos. Repare-se que a quase inexistência de concorrência veio concentrar o esforço do CA mais no cumprimento da primeira meta do que no da segunda, praticamente garantida. Aliás, o relatório estabelece como objetivo "abrir o Teatro Nacional de São Carlos, frequentado por um público de habitués ao longo dos anos, à sociedade civil", chegando, ainda assim, a reconhecer dificuldades à "renovação das gerações" e à "formação de novos públicos" (Ibidem: 32), resultantes da elevada taxa de renovação de assinaturas.

$7 \mathrm{O}$ que não dispensa a aprovação de planos de atividades anuais e plurianuais por parte das respectivas tutelas (Art. ${ }^{\circ}$ 8).

${ }^{8}$ Com formação académica em gestão e organização de empresas, políticas e gestão de recursos humanos, Pedro Santos Moreira foi diretor da licenciatura em Gestão de Recursos Humanos e integrou a Comissão Executiva do Departamento de Ciências de Gestão do Instituto Superior de Ciências do Trabalho e da Empresa. 
A par do aumento do número de eventos, a receita de sucesso do empreendimento compreendia: o melhor aproveitamento de recursos, inclusive do trabalho dos artistas (através, por exemplo, de realização de espetáculos que reunissem elencos de ambos os organismos); o aumento das receitas próprias, com destaque para o protocolo de mecenato estabelecido entre o TNSC e o Millenium-BCP, no valor de um milhão de euros (período 2008-2009); a rentabilização do "espaço nobre" por via do seu aluguer para eventos; a venda de espetáculos de menor dimensão a autarquias ou, ainda, a "possibilidade, sujeita à aprovação da tutela, de aumento dos preços dos bilhetes no TNSC" (Ibidem: 35).

Por fim, a concretização destes objetivos seria facilitada por uma empresa que se atribuía uma organização mais eficiente e um conjunto de funcionários devidamente qualificados. Tanto o TNSC como a CNB, de acordo com o relatório citado, não possuíam até à data um organigrama pré-definido, organizando-se antes "por um sistema de gestão típico de empresas familiares tradicionais de média dimensão [com] todo o poder concentrado no topo, ausência de uma linha hierárquica (...), um centro operacional estruturado adhocraticamente em função do poder informal dos atores (...)" (Ibidem: 13).

O modelo de organização proposto apresentava como núcleo central o projeto - de carácter artístico ou infra-estrutural - devendo o mesmo resultar da articulação entre o seu gestor e as áreas de suporte (recursos humanos, marketing, etc.).

A transformação de um instituto em empresa pública assinala uma significativa mudança de paradigma na providência de serviços públicos. À semelhança do que sucede na União Europeia (e do que tem sido promovido através do controlo das despesas orçamentais), os princípios de gestão empresarial, agrupados sob a categoria de Nova Gestão Pública, foram gradualmente introduzidos no domínio público, em áreas como a saúde e a educação: a profissionalização da gestão; a preocupação com a contenção de custos (o 'fazer mais com menos'); a descentralização das unidades; a definição de objetivos de produção e avaliação do desempenho quer dos trabalhadores, quer da própria empresa; ou a defesa do contrato individual em detrimento dos contratos coletivos de trabalho (Carvalho, 2009: 52-57). A estes acrescentamos, dada a especificidade do objeto em questão, a procura de fontes de financiamento alternativas, prioritariamente do setor empresarial.

A aplicação deste programa de gestão não deixou, contudo, de ser polémica. O privilégio de um critério - a capacidade de gerar capital - implicará a secundarização dos restantes. Neste sentido, a redução de custos poderá depender "tão só, do 
inegociável: abaixamento da performance técnico-artística, insatisfação da boa parte dos seus públicos [...], descredibilização da organização junto das suas congéneres, desmotivação dos corpos artísticos, etc.” (Mira, 2011: 171) 9 .

A decisão de alteração do estatuto do TNSC provocou, logo em 2007, a demissão do que era, à época, o diretor artístico, Paolo Pinamonti (n.1958) ${ }^{10}$. Na carta endereçada às autoridades competentes, o musicólogo e maestro italiano terá justificado a sua decisão com base na situação financeira da instituição e nas novas condições de gestão previstas (apud Carvalho, 2011: 173). De facto, a constituição do OPART decorreu num contexto de constrangimento financeiro, cenário que não só nunca se inverteu, como viria a agravar-se. Em finais de 2009, o relatório de contas da empresa pública fazia alusão "ao redobrado esforço de contensão", fruto quer do contexto macroeconómico, quer da condição deficitária da empresa desde a sua criação. Tal esforço conduzia, por exemplo, "ao adiar de despesas e investimentos importantes no médio prazo", em particular nalgumas "contratações urgentes do ponto de vista artístico (bailarinos, equipa técnica e artística) que estavam previstas no orçamento logo desde o início do ano" (OPART, 2009: 7). No ano seguinte, já sob nova direção, de Jorge Salavisa (n.1939) 11 , o CA classificava a situação da tesouraria como "preocupante", impossibilitando investimentos prioritários e atrasando os pagamentos a trabalhadores e fornecedores, algo que "põe seriamente em causa a capacidade negocial e o bomnome, nacional e internacional, do OPART" (OPART, 2010: 4) ${ }^{12}$.

Embora a posição financeira da empresa tenha sido instável desde o seu primeiro momento, esta situação explica-se, em parte, pelos montantes de mecenato abaixo do conjeturado. Logo em 2008, a instituição admitia que, não obstante a previsão de contribuições da parte do Millennium BCP na ordem de 1 milhão de euros, estas haviam sido reduzidas a metade deste valor (OPART, 2008: 4). Um ano depois, os dados contidos no relatório de contas do $3 \cdot{ }^{\circ}$ trimestre indicavam a manutenção dos valores do mecenato abaixo da previsão realizada, apesar dos subsídios à exploração concedidos pela Fundação Ernst von Siemens à ópera Agrippina, e pelo Turismo de Portugal ao Festival ao Largo (OPART, 2009: 8-9). Finalmente, verificar-se-ia a diminuição dos contributos mecenáticos de 7,5\% dos rendimentos em 2010 (abaixo das

\footnotetext{
${ }^{9}$ José António Mira é mestre em Administração e Políticas Públicas e músico na Orquestra Sinfónica Portuguesa.

${ }^{10}$ Pinamonti viria a ser novamente contratado pelo TNSC, enquanto consultor artístico, em meados de 2013.

${ }^{11}$ Jorge Salavisa foi diretor artístico do Ballet Gulbenkian, diretor da CNB e diretor artístico do São Luiz Teatro Municipal.

$12 \mathrm{O}$ valor da Indemnização Compensatória (transferência do Orçamento de Estado para a instituição) terse-á mantido na ordem dos 18 milhões de euros ao longo de 2008, 2009 e 2010 (OPART 2010, 3).
} 
previsões) para 5,6\% em 2011, devido à diminuição dos apoios concedidos pelo Milennium BCP (OPART, 2010: 7; OPART, 2011: 57).

Se ao longo da década de 90 a prática do mecenato se circunscreveu a grandes empresas - banca e seguros, em particular -, um fenómeno que pode ser atribuído ao débil parque empresarial (Santos, 2012), a crise económica de 2008 e o seu impacto no mundo financeiro viria a obrigar a uma redução de custos generalizada. Num balanço final, podemos constatar que quer a percentagem dos contributos dos mecenas, quer a receita garantida pelas bilheteiras, 5\% em 2011 (OPART, 2011: 57), tornam inevitável a quase exclusiva dependência de fundos públicos.

O agravamento da crise económico-financeira em Portugal no ano de 2011, marcado pela assinatura de um programa de austeridade entre governo e Troika ${ }^{13}$ e por eleições legislativas antecipadas ${ }^{14}$, gerou uma profunda instabilidade na empresa. Meses após o anúncio da intenção de extinguir o OPART por parte da então ministra da Cultura, Gabriela Canavilhas (n.1961), defensora da criação de um Agrupamento Complementar de Empresas no setor cultural, o TNSC e a CNB seriam obrigados a uma redução da atividade (Público, 2011).

Sob as linhas gerais de orientação do Plano de Redução e Melhoria da Administração Central (PREMAC), aprovado pelo XIX governo, em julho de 2011 - visando reduzir os custos da Administração Central do Estado e a implementação de modelos de gestão privada - o TNSC será transformado numa empresa pública e integrado num Agrupamento Complementar de Empresas (Decreto-Lei $n^{0}$ 208/2012, de 7 de setembro).

Apesar do seu fim à vista, coube ao OPART não só assumir a gestão dos dois organismos como também planear a transferência de competências para a prevista nova estrutura, a GESCULT - Serviços Partilhados na Cultura, ACE. Num contexto de aplicação de medidas de austeridade, o financiamento público contemplado sofreu uma diminuição na ordem dos 20\% em 2012 (OPART, 2012: 6) ${ }^{15}$, levando a empresa para o "limiar da sobrevivência" (Ibidem: 6). A situação, segundo o Conselho de Administração, era especialmente preocupante no respeitante ao TNSC, podendo mesmo "estar a assistir-se ao fim do modelo de casa de ópera que o TNSC foi desde a sua génese" (Ibidem: 6).

13 Grupo trilateral composto por Comissão Europeia, Fundo Monetário Internacional e Banco Central Europeu.

14 Decorrentes da não aprovação do Plano de Estabilidade e Crescimento (PEC) IV pelo Parlamento e consequente demissão do governo. O PSD sairia vencedor das eleições, tendo constituído um governo de coligação juntamente com o PP.

15 O relatório de contas de 2012 encontra-se publicado, embora não tenha sido sujeito a aprovação. 
A criação do TNSC, E.P.E decorre, de acordo com o estatuto providenciado pelo Decreto-Lei ${ }^{0}$ 208/2012, de 7 de setembro, que instituiu a GESCULT, da necessidade de articular "os objetivos de racionalização de recursos" com a "especificidades próprias" (Decreto-Lei n. ${ }^{0}$ 208/2012, de 7 de setembro) inerentes a cada organismo. As mudanças, contudo, tendiam a limitar-se a uma reorganização das competências de gestão, não contemplando a forma de governo da instituição. Apesar de o TNSC passar a auferir do seu próprio CA, uma grande parte dos poderes de gestão - inclusive a recolha de apoios mecenáticos - seriam da responsabilidade do GESCULT, à semelhança do que acontecia com as outras empresas públicas integradas neste agrupamento (a CNB, a Cinemateca Portuguesa, o Teatro Nacional D. Maria II e o Teatro Nacional S. João).

O cariz mais formal do que material das alterações empreendidas, dado que se mantém o estatuto de empresa pública, poderá explicar, em primeiro lugar, a quase indiferença com que a suspensão da GESCULT (Decreto-Lei $n^{0}$ 36/2013, de 11 de março) e o consequente regresso às funções do OPART foram recebidos; e, em segundo lugar, a perpetuação do cenário de crise em que o TNSC se encontrava. Note-se que o diploma que suspendeu a GESCULT não explicitou os motivos da deliberação, deixando a incógnita quanto a futuros modelos para o $\mathrm{TNSC}^{16}$.

Aproximadamente um ano após esta medida, o secretário de estado da Cultura, Jorge Barreto Xavier (n.1965), anunciou que o TNSC ficaria sem a figura de diretor artístico no próximo triénio (Costa, 2014). Contará, no seu lugar, com um “consultor para a programação" do teatro, papel atribuído a Paolo Pinamonti, o atual diretor do Teatro de la Zarzuela, em Madrid, e o programador-empresário possível para o único teatro de ópera do país, numa opção justificada pelo "conhecimento da organização e o seu historial" e pela posse de uma "rede de contactos internacional" (Ibidem).

\section{Conclusão}

Da análise desenvolvida em torno da evolução dos estatutos do TNSC e dos seus figurinos de gestão retiram-se algumas ideias principais. Em primeiro lugar, ressalta a continuada tentativa do Estado na definição de um enquadramento legal capaz de conjugar as suas responsabilidades no apoio à preservação patrimonial, bem como à promoção da criação e produção artística, com as oscilações de recursos financeiros

\footnotetext{
${ }^{16}$ Num artigo publicado no jornal Público, o crítico cultural Augusto M. Seabra interpreta esta decisão com base na polémica à volta do subfinanciamento da Cinemateca. A GESCULT supunha cada uma das instituições integradas no seu seio "como entidades empresariais, e nesse sentido impossibilitadas de qualquer recurso adicional que pudesse provir da Direcção-Geral do Orçamento" (Seabra 2013, online). A sua suspensão garantiu assim o regresso da Cinemateca ao estatuto de instituto público e, por conseguinte, $\mathrm{o}$ acesso direto a financiamento adicional.
} 
(públicos e privados), sem os quais não há sustentabilidade do teatro e das suas formações artísticas. A questão 'O que fazer de S. Carlos'?, colocada desde a I República (Seabra, 1993), repete-se com particular intensidade desde 2008, em contexto de fortes restrições orçamentais nas finanças públicas e de algum abrandamento da participação privada na cultura.

Repare-se também no modo como evolui a correspondência entre opções dos governos e as suas orientações ideológicas. Se, na década de 90, é ainda visível a distinção quanto às escolhas dos executivos socialista e social-democrata - o primeiro adotando a figura do instituto público e autónomo (embora integrando alguns ditames da gestão privada), o segundo tendendo preferencialmente a adotar modelos de desestatização -, nos anos 2000 verifica-se a confluência de ambos em práticas da denominada Nova Gestão Pública. O projeto da criação de um agrupamento complementar de empresas para a área da cultura vem demonstrar tal aproximação, a que não é alheia a conjuntura de crise comummente atravessada.

Como se viu, a partir de meados da década de 80 e ao logo dos anos 90, as alterações estatutárias do TNSC irão acompanhar as tendências de crescente inter-relação entre as esferas da cultura e da economia, por um lado, e de progressiva integração, no trabalho artístico, de lógicas empresariais e da superação da tradicional incompatibilidade ideológica entre artistas e empresários, por outro. A transformação do TNSC em empresa pública, em 1980, e sobretudo, mais tarde, a passagem a fundação, surgem fundamentadas em dois princípios fundamentais: a crença na maior eficácia de um tipo de gestão privada, face àquela tradicionalmente praticada pelo Estado; e, concomitantemente, o distanciamento da ideia de financiamento da cultura assegurado exclusivamente pelo Estado.

Esta lógica, em consonância com a aprovação da Lei do Mecenato em 1986, não obteve, contudo, os resultados esperados. Ao analisarmos os diversos preâmbulos dos regimes legais do TNSC deparamo-nos, face à distância entre o almejado e o realmente alcançado, com constantes reavaliações das estratégias empreendidas, as quais, em geral, denotam quão delicada é a relação entre a promoção da cultura e a defesa da sua abertura ao mercado. Mesmo a decisão de vincular o TNSC a um modelo de instituto público, em 1998 - num contexto, novo, de reconhecimento e afirmação de uma política autónoma para a cultura e de aumento de financiamento público nesta área não deixou de procurar a aproximação a algumas linhas da gestão privada. Seria, mais tarde, com a fusão do TNSC e do CNB no OPART, que os princípios da Nova Gestão Pública seriam postos em prática de modo pleno. O seu acento na lógica de projetos parece confirmar a tendência analisada por Boltanski e Chiapello, segundo a qual tanto 
as empresas, independentemente do seu cariz, como a própria sociedade como que dão corpo a uma amálgama de projetos em rede, os quais "exigem um certo compromisso (...) e pressupõem a monitorização por outros participantes das qualidades que todos devem colocar em prática” (Boltanski e Chiapello, 2007: 107).

O caso da gestão do TNSC evidencia como a passagem de "axiomas não testados" (Carvalho 2009: 32) ao plano prático pode ser problemática. Num contexto de recessão económica e de austeridade, a confiança quer nos resultados produzidos por uma gestão de tipo privada, quer nos benefícios provenientes da responsabilidade social mecenática revelou ser excessiva nas suas expectativas. A julgar pela situação do TNSC nos mais recentes anos, é a própria sobrevivência da instituição e da sua identidade incluindo o que respeita à programação de um teatro de ópera e aos perfis profissionais que requer - que se encontra em jogo. Permanece, pois, por resolver o dilema central deste teatro, já diagnosticado aquando do seu bicentenário, em 1993 (Seabra, 1993): fazer parte de circuitos internacionais e promover intérpretes locais, conjugando as vertentes de exibição e produção.

\section{Referências Bibliográficas}

Atkinson, Paul (2006) Everyday Arias: An Operatic Ethnography. Lanham MD: AltaMira Press.

Bakhtin, Mikhail (2007) Speech genres and other late essays. Austin: University of Texas Press.

Bolstanski, Luc, \& Chiapello, Eve (2007) The new spirit of capitalism. Londres: Verso.

Brito, Manuel Carlos (1989) Opera in Portugal in the Eighteenth Century. Cambridge University Press.

Câmara, Maria João (2013) Maria José Nogueira Pinto. Uma vida invulgar. Lisboa: Oficina do Livro.

Carvalho, Mário Vieira (2011) "Macdonaldização da comunicação e arte como fast food: sobre a recepção de Das Märchen”, Correia, Alda, Fragoso, Gabriela, Ribeiro, Fernando \& Canaveira, Manuel (eds.), A Arte da Cultura (Homenagem a Yvette Centeno). Lisboa: Colibri, pp. 169-196. 
Carvalho, Mário Vieira (1993) Pensar é Morrer. O Teatro de São Carlos. As mudanças de sistemas sociocomunicativos desde fins do séc. XVIII aos nossos dias. Lisboa: Imprensa Nacional - Casa da Moeda.

Carvalho, Teresa (2009) Nova Gestão Pública e Reformas de Saúde. Lisboa: Sílabo.

Costa, Tiago Bartolomeu (2014) “A nova vida do São Carlos só vai ter Pinamonti como consultor”. Público (online). http://www.publico.pt/culturaipsilon/noticia/a-novavida-do-sao-carlos-sem-director-artistico-mas-um-consultor-de-peso-paolopinamonti-1627311 (consultado em 25 de outubro de 2014).

Cruz, Manuel Ivo (1992) O Teatro Nacional de S. Carlos. Porto: Lello.

Cruz, Manuel Ivo (2008) O Essencial sobre a Ópera em Portugal. Lisboa: Imprensa Nacional - Casa da Moeda.

Cummings, M.C., \& Katz, R.S (1989) "Relations between government and the arts in Western Europe and North America” Cummings, Jr., M.C \& Schuster, J.M.D (eds.), Who's to pay for the arts? The international search for models of arts support. New York: ACA Books, American Council for the Arts, pp.5-14.

Cymbron, Luísa (2009) "Teatro Nacional de São Carlos", Castelo-Branco, Salwa, Enciclopédia da música em Portugal no século XX.Lisboa: Círculo de Leitores, pp. $1253-1255$.

Dionísio, Eduarda (1993) Títulos, Ações e Obrigações: a cultura em Portugal (19741994). Lisboa: Edições Salamandra.

Domingos, Nuno (2007) A Ópera do Trindade: O papel da Companhia Portuguesa de Ópera na "política social" do Estado Novo. Lisboa: Lua de Papel/INET.

Garcia, José Luís (coord.), Lopes, João Teixeira, Neves, José Soares, Gomes, Rui Telmo, Martinho, Teresa Duarte, \& Borges, Vera (2014) Mapear os recursos, levantamento da legislação, caracterização dos atores, comparação internacional. Lisboa: GEPAC/Secretário de Estado da Cultura. http://www.gepac.gov.pt/cultura2020.aspx.

Henriques, Eduardo Brito (2002) "Novos Desafios e Orientações das Políticas Culturais: Tendências nas Democracias Desenvolvidas e Especificidades do Caso Português”, Revista Finisterra, 73 (37): 61-80. 
Hespanha, António (1997) Panorama Histórico da Cultura Jurídica Europeia. Mem Martins: Publicações Europa-América.

Marques, Maria Manuel Leitão (1990) “A Constituição Económica Portuguesa depois da Revisão Constitucional de 1989”, Oficina do CES, 16, Coimbra, Centro de Estudos Sociais. http://www.ces.uc.pt/publicacoes/oficina/ficheiros/16.pdf

Martins, Moisés Lemos (2002) A linguagem, a verdade e o poder: ensaio de semiótica social. Lisboa: Fundação Calouste-Gulbenkian.

Martorella, Rosanne (1982) The Sociology of Opera. Nova Iorque: Praeger.

Menger, Pierre Michel (1999) “Artistic Labor Markets and Careers”, Annual Review of Sociology, Vol. 25: 541-574.

Mira, José António (2011) "A gestão de qualidade nos teatros de ópera públicos", Mozzicafreddo, Juan \& Gomes, João Salis (Eds.) Projectos de Inovação na Gestão Pública. Lisboa: Mundos Sociais, pp.163-176.

Morató, Artur Rodríguez (2010) “A metamorfose do valor cultural na sociedade contemporânea: desafios e paradoxos”, Pais, José Machado, Santos, Maria de Lourdes (Eds.), Novos Trilhos Culturais: Práticas e Políticas. Lisboa: Imprensa de Ciências Sociais, pp. 37-50.

Moreau, Mário (1999) O Teatro de S. Carlos. Dois séculos de História. Lisboa: Hugin Editores.

Mozzicafreddo, Juan, Gouveia, Carla (2011) "Contextos e Etapas de Reforma na Administração Pública em Portugal”, Mozzicafreddo, Juan \& Gomes, João Salis (Eds.) Projectos de Inovação na Gestão Pública. Lisboa: Mundos Sociais, pp.5-62.

Público (2011) "Opart anuncia redução temporária da actividade”, Público (online). http://www.publico.pt/culturaipsilon/noticia/opart-anuncia-reducao-temporaria-daactividade-1516320 (consultado em 25 de outubro de 2014).

Ramos, José Luís Bonifácio (2011) "O Ministério da Cultura e as Políticas Culturais" , Gomes, Gomes, Carla Amado, \& Ramos, José Luís Bonifácio (coords.), Direito da Cultura e do Património Cultural. Lisboa: Associação de Estudantes da Faculdade de Direito da Universidade de Lisboa, pp. 249-315. 
Ribeiro, Paula Gomes (2012) "Pensar a Revolução, nos Comportamentos e Práticas Culturais Associadas ao Teatro de São Carlos entre o Fim do Estado Novo e os Primeiros Anos da Democracia em Portugal”, Revista Música Hodie, 12 (2): 48-56.

Santos, Maria de Lourdes Lima \& Conde, Idalina (1990) "Mecenato cultural de empresa em Portugal”, Análise Social, vol. XXV (107), (3. $\left.{ }^{\circ}\right)$ : 375-439.

Santos, Maria de Lourdes Lima (coord.) (1998) As Políticas Culturais em Portugal. Lisboa: Observatório das Actividades Culturais.

Santos, Maria de Lourdes Lima (2012) Sociologia da Cultura. Perfil de uma carreira. Lisboa: Imprensa de Ciências Sociais.

Seabra, Augusto M. (2013) “Cinemateca, um debate imprescindível”, Público (online). http://www.publico.pt/opiniao/jornal/cinemateca-um-debate-imprescindivel27216161 (consultado em 25 de outubro de 2014).

Seabra, Augusto M. (1993) Ir a S. Carlos. Lisboa: Clube do Colecionador dos Correios.

Silva, Augusto Santos (2003) "Como classificar as políticas culturais? Uma nota de pesquisa”, Obs, 12, Observatório das Actividades Culturais: 10-20.

\section{Legislação}

Decreto-Lei no 35775 , de 31 de julho de 1946

Decreto-Lei $\mathrm{n}^{0} 533 / 79$, de 31 de dezembro

Decreto-Lei $\mathrm{n}^{0}$ 259/80, de 5 de agosto

Decreto-Lei ${ }^{0}$ 258/86, de 28 de agosto

Lei Constitucional $n^{0} 1 / 89$ de 8 de julho

Decreto-Lei no 88/98, de 3 de abril

Decreto-Lei no 74/99, de 16 de março

Lei $\mathrm{n}^{0}$ 32-B/2002, de 30 de dezembro

Decreto-Lei $\mathrm{n}^{0}$ 160/2007, de 27 de abril

Decreto-Lei no 108/2008, de 26 de junho

Decreto-Lei ${ }^{0}$ 208/2012, de 7 de setembro 
Decreto-Lei no $36 / 2013$, de 11 de março

\section{Programas governamentais}

Programa do III governo provisório. http://www.portugal.gov.pt/pt/ogoverno/arquivo-historico/governos-provisorios

$\begin{array}{lllll}\text { Programa } & \text { do } & \mathrm{X} & \text { governo } & \text { constitucional. }\end{array}$

http://www.portugal.gov.pt/media/464036/GC10.pdf

\section{Relatórios de Contas (OPART)}

OPART (2007). Relatório de Gestão e Contas 2007. Disponível em http://tnsc.pt/wpcontent/uploads/2013/01/opart.relatorioecontas2007.pdf

OPART (2008). Relatório Trimestral $-3 \cdot^{\circ}$ Trimestre 2008. Disponível em http://tnsc.pt/wp-content/uploads/2013/01/opart.trimestre3.2008.pdf

OPART (2009). Relatório Trimestral $-3 .^{\circ}$ Trimestre 2009. Disponível em http://tnsc.pt/wp-content/uploads/2013/01/opart.trimestre3.2009.pdf

OPART (2010). Relatório Trimestral $-33^{\circ}$ Trimestre 2010. Disponível em http://tnsc.pt/wp-content/uploads/2013/o1/opart.trimestre3.2010.pdf

OPART (2011). Relatório de Gestão e Contas 2011. Disponível em http://tnsc.pt/wpcontent/uploads/2013/03/opart.relatorioecontas2011.pdf

OPART (2012). Relatório de Gestão e Contas 2012 [A Aguardar Aprovação]. Disponível em http://tnsc.pt/wp-content/uploads/2013/o1/Relatorio-e-Contas-OPArt2012-a-aprovar.pdf

Teresa Duarte Martinho é investigadora de pós-doutoramento no ICS-ULisboa, com o apoio da FCT. Interesses e áreas de investigação: profissões e ocupações culturais e artísticas; políticas culturais; mediação da arte e da ciência; arte e tecnologia; cultura digital. Licenciada e doutorada em Sociologia pelo ISCTE, onde também obteve o grau de mestre em Comunicação, Cultura e Tecnologias da Informação. Entre 1996 e 2011, integrou a equipa de investigadores do Observatório das Actividades Culturais, criado por iniciativa do Ministério da Cultura. Jornalista entre 1990 e 1996, na revista Marie Claire, com trabalho focado no sector da cultura e das artes. teresa.duartemartinho@ics.ul.pt

José Nuno Matos, licenciado e mestre em Ciência Política pelo ISCSP-UTL, é doutorado em sociologia no Instituto de Ciências Sociais da Universidade de Lisboa (ICS-ULisboa), com a tese O Operário em Construção: das Relações Humanas ao Trabalho Temporário. Encontra-se presentemente a desenvolver um projeto de pós-doutoramento, no ICS-ULisboa, em torno da relação entre a prática jornalística e a precariedade. Tem dedicado os seus estudos às questões do trabalho, do sindicalismo e dos movimentos sociais. mor furtado@yahoo.com 